\title{
O Caminho da Violência pelas Narrativas Jornalísticas: A Patologização do Machismo
}

\author{
Ana Paula de Castro Neves \\ Doutoranda do Programa de Pós- \\ Graduação Interdisciplinar em Direitos \\ Humanos da Universidade Federal de \\ Goiás (PPGIDH-UFG). \\ E-mail: anapaula_castro@discente.ufg.br
}

\section{Angelita Pereira de Lima}

Doutora em Geografia pela Universidade Federal de Goiás (UFG).

Professora do Programa de PósGraduação Interdisciplinar em Direitos Humanos (PPGIDH) da UFG. Atualmente é Reitora da UFG.

E-mail: angelita_lima@ufg.br

\section{Luciano Rodrigues Castro}

Bacharel em Comunicação Social, com habilitação em Jornalismo, pela Universidade Federal de Goiás. É Mestre e Doutorando em Direitos Humanos pela mesma instituição.

E-mail: ro.luciano88@gmail.com
Resumo: Este trabalho apresenta uma análise sobre a patologização do machismo por meio das narrativas dos jornais O Popular e Diário da Manhã de 2016 e 2017. Procura-se categorizar a construção e os argumentos dessas narrativas no que tange à temática da violência de gênero e do processo de revitimização. Para tanto, buscou-se articular leituras de gênero, comunicação e direitos humanos com o fito de evidenciar a ocorrência de violência de gênero no processo de revitimização das mulheres violentadas, convertidas em objeto de representações jornalísticas. A forma como as mulheres em situação de violência foram abordadas nas matérias analisadas denotou que estas apresentam conteúdos e narrativas estruturadas a partir de regimes simbólicos correntes em outros campos da vida social que naturalizam relações violentas e desiguais. Assim, as dinâmicas jornalísticas também assumem o papel de agentes de violência - numa dimensão simbólica - nesse processo, em que se encontra a dinâmica da revitimização midiática.

Palavras-chave: violência contra mulheres, revitimização, violência institucional de gênero, patologização do machismo, jornais O popular e Diário da manhã.

\section{El Camino de la Violencia en las Narrativas Periodísticas: La Patologización del Machismo}

Resumen: Este trabajo analizó la patologización del machismo en las narrativas de los periódicos O Popular y Diário da Manhã en el periodo del 2016 al 2017. Se busca categorizar la construcción y los argumentos de las narrativas sobre la violencia de género y el proceso de revictimización. Por ello, se articulan lecturas de género, comunicación y derechos humanos con el fin de resaltar la ocurrencia de violencia de género en el proceso de revictimización de mujeres violadas, convertidas en objetos de representaciones periodísticas. Los artículos periodísticos sobre las mujeres en situaciones de violencia presentan contenidos y narrativas estructuradas a partir de regímenes simbólicos vigentes en otros campos de la vida social que naturalizan las relaciones violentas y desiguales. Así, las dinámicas periodísticas también asumen el papel de agentes de violencia -en una dimensión simbólica-en este proceso, en que se encuentra la dinámica de revictimización de los medios.

Palabras clave: violencia contra la mujer, revictimización, violencia institucional de género, patologización del machismo, periódicos $O$ popular y Diário da Manhã.

\section{The Path of Violence through Journalistic Narratives: The Pathologization of Machism}

Abstract: This work shows a general analysis on the pathologization of machismo by narratives of newspapers O Popular and Diário da Manhã from 2016 to 2017. It seeks to categorize the construction and the arguments of these narratives regarding the theme of gender violence and the re-victimization process. To this end, we sought to articulate readings of gender, communication, and human rights aiming to show the occurrence of gender violence in the process of re-victimization of abused women, converted into the object of journalistic representations. The ways in which women in situations of violence were approached in the analyzed materials showed that they present content and narratives structured from symbolic regimes current in other fields of social life which naturalize violent and unequal relationships. Thus, the journalistic dynamics also assume the role of agents of violence - in a symbolic dimension - in this process, where the dynamics of media re-victimization is found. 


\section{Introdução}

O levantamento dos dados que constituem a base de análise deste artigo foi feito a partir da pesquisa $A$ culpabilização das mulheres nas narrativas sobre violência de gênero nos boletins de ocorrência e nos jornais diários de Goiânia (Neves \&

${ }^{1}$ Grupo de Pesquisa Benedita Tatu código PV0867-2017 -, é um grupo de pesquisa acadêmica da FIC-UFG, sem financiamento, coordenado pela Profa. Dra. Angelita Pereira de Lima, cujo objetivo é estudar a culpabilização das mulheres nas narrativas sobre violência de gênero nos boletins de ocorrência e nos jornais diários de Goiânia. O grupo é composto de estudantes e pesquisadores do Jornalismo, do Direito e da Saúde e recebeu esse nome em homenagem à goiana Benedita Tatu, que, além de ter uma história de vida fascinante, com altos e baixos, morreu vítima de violência de gênero. A sua morte, como tantas outras, foi invisibilizada pelas autoridades. Maiores detalhes sobre a história de Benedita Tatu podem ser encontrados em: https://www.xapuri.info/universofeminino/benedita-tatu/.

${ }^{2} A$ revitimização é um reflexo da violência de gênero institucional, que decorre do sofrimento continuado ou repetido das mulheres em situação de violência e ocorre, principalmente, nas esferas institucionais - em delegacias, no Ministério Público e no Judiciário (Cunha \& Pinto, 2008), quando a vítima busca a tutela jurisdicional como meio de amparo social para que esta Ihe confira a real proteção ao direito. Porém, a vítima não encontra nos entes públicos o devido respaldo, muito menos é assegurada e protegida legalmente contra a violência de gênero, o que gera mais uma vitimização, acrescida de impunidade e insegurança. Moreira, 2021), que se encontra em fase de finalização no grupo Benedita Tatu ${ }^{1}$, coordenado pela professora Angelita Pereira de Lima, no âmbito da Faculdade de Informação e Comunicação da Universidade Federal de Goiás (FIC-UFG). Diversos produtos derivam de tal pesquisa, dentre elas a dissertação de mestrado Além das narrativas jornalísticas e policiais: uma análise sobre a revitimização das mulheres em situação de violência de gênero institucional (Neves, 2021), que desenvolveu as categorias basilares deste artigo.

Como material para análise, elencou-se um total de onze notícias do jornal O Popular - seis de 2016 e cinco de 2017 - e seis notícias do jornal Diário da Manhã - duas de 2016 e quatro de 2017. Para realizar o exame das notícias, utilizouse a análise de conteúdo (AC) de Bardin (2016), com abordagem qualitativa. A AC, segundo a pesquisadora na edição revisada e atualizada de sua obra, é:

Um conjunto de instrumentos metodológicos cada vez mais sutis em constante aperfeiçoamento, que se aplicam a "discursos" (conteúdos e continentes) extremamente diversificados. O fator comum dessas técnicas múltiplas - desde o cálculo de frequências que fornece dados cifrados, até a extração de estruturas traduzíveis em modelos - é uma hermenêutica controlada, baseada na dedução: a inferência. Enquanto esforço de interpretação, a análise de conteúdo oscila entre os dois polos do rigor da objetividade e da fecundidade da subjetividade. (Bardin, 2016, p. 15)

A AC, segundo a autora, é composta de diferentes fases, organizadas em três polos cronológicos: pré-análise; exploração do material; o tratamento, a inferência e a interpretação dos resultados. A pré-análise é feita a partir da escolha dos documentos que serão submetidos à análise, da formulação de hipóteses e dos objetivos e da elaboração de indicadores que fundamentam a interpretação final (Bardin, 2016). Esse processo, que resultou neste artigo, foi desenvolvido por meio da seleção, da organização e do tratamento de notícias sobre violência contra as mulheres, publicadas em 2016 e 2017, nos jornais diários de Goiânia O Popular e Diário da Manhã. Ademais, foram desenvolvidas categorias de análise a partir da exploração do material.

Neste artigo, apresentamos uma categoria revelada constante na dissertação de Neves (2021) que reproduz uma visão limitada acerca da violência de gênero, a saber: a patologização do machismo. A abordagem encontrada nos noticiários e nas narrativas de jornais resulta no processo de revitimização ${ }^{2}$, que ocorre quando as mulheres permanecem no ciclo de violência.

Metodologicamente, explica-se que as palavras, os termos ou as imagens que estigmatizam mulheres em situação de violência foram selecionadas a partir de três categorias: a desqualificação da mulher; a passionalidade; e a patologização do machismo. Para os fins deste artigo, consideramos apenas a última. Assim, extraíram-se algumas unidades de registro - termos utilizados pelos jornais -, como o comportamento inadequado da mulher, a motivação alegada pelo agressor e as imagens, a partir da leitura exploratória das notícias jornalísticas, para a realização da análise de conteúdo.

Por meio desses elementos, acredita-se que é possível evidenciar a forma como os depoimentos das mulheres foram construídos a partir das fontes de informação - as narrativas policiais, por exemplo -, bem como reproduzidos e publicizados pelas narrativas jornalísticas. Tais unidades de análise, conforme Bardin (2016), foram agrupadas de maneira a permitir uma leitura crítica das notícias, seguida pela verificação do processo de revitimização. A patologização do machismo é uma categoria que emerge dessa leitura crítica e se apresenta como forma hegemônica de explicar/justificar as relações de causa e efeito da violência contra as mulheres. A presença dessa categoria nas narrativas jornalísticas e seus efeitos na violência institucional de gênero é o problema de reflexão que nos guia neste artigo. 
${ }^{3}$ As substâncias psicoativas (SPAs) são drogas que, segundo a Organização Mundial da Saúde (OMS), são “... qualquer substância não produzida pelo organismo que tem a propriedade de atuar sobre um ou mais de seus sistemas, causando alterações em seu funcionamento" (“Drogas”, s.d., p. 1).

\section{Desenvolvimento}

Para Rabenhorst (2010, p. 122 citado por Moura, 2017, p. 45), por trás “de uma aparente neutralidade das categorias jurídicas, como se vê, esconde-se uma adesão prévia ao patriarcado". Nesse contexto, o argumento de que o uso de bebidas alcoólicas e de drogas ilícitas ${ }^{3}$ são responsáveis pelas agressões praticadas pelos homens é bastante utilizado pelos jornais e naturalmente aceito pela sociedade e, muitas vezes, pelas próprias mulheres vítimas (Lima, 2001). Assim, o uso indevido de bebidas ou drogas, reproduzido pela mídia como fator causador ou determinante da violência contra mulheres, vem sendo naturalizado como justificativa para a agressão, alimentando, assim, o discurso dominante.

Neste aspecto, segundo Saffioti (2004), os problemas com dinheiro e álcool são apenas facilitadores do processo de violência, ou seja, esses fatores, em sua maioria, servem apenas como potencializadores da violência de gênero e estão associados, por exemplo, ao machismo, à dominação masculina, ao sexismo e à misoginia. Em face disso, a relação direta entre violência e uso de bebidas alcoólicas comumente funciona como "justificativa", mas também como forma de mascarar conflitos de gênero (Lima, 2001).

Quando a notícia naturaliza a violência como algo cotidiano e reproduz as concepções de que o álcool e as drogas explicam as atitudes do agressor, estamos diante de uma construção social em que existe apenas a relação entre as substâncias psicoativas e a violência contra mulheres. Em tal construção, excluise a necessidade de reflexões sobre a violência como uma ação que transforma diferenças em desigualdades hierárquicas com o fim de dominar, explorar e oprimir (Chauí, 1985).

Entende-se que a violência contra mulheres está enraizada socialmente, em um contexto perpassado pela dominação masculina, o que inclui os meios de comunicação que se revelam agentes deste processo por meio de sua produção simbólica (Bourdieu, 2019; Lamas, 2000). Para Bandeira (2014, p. 457):

A violência de gênero é demarcada na carne e não é sutil, porém, mais forte é a demarcação simbólica, que, quando quebrada, responde com a morte, uma vez que não podemos romper como reprodutoras da ordem social e biológica que nos foi imposta... Ainda assim trazem consigo significados e desdobramentos importantes para que se possa compreender a manutenção dos ordenamentos familiares, uma vez que não está rompida a máxima: "em briga de marido e mulher, ninguém mete a colher". Se a luta do movimento feminista foi tornar pública a violência sofrida pelas mulheres, no sentido de reconhecê-la como problema que envolve a sociedade em geral, o poder familiar ainda a silencia.

A patologização do machismo, a nosso ver, decorre desse tipo de abordagem, que, por sua vez, é compreendida como o processo pelo qual a responsabilidade pela agressão cometida é simbólica e socialmente atenuada ou extinta, a partir da constatação de que o perpetrador agiu sob a influência de substâncias psicoativas.

Frente $a$ isso, as diferenças e assimetrias são sempre transformadas em desigualdades que reforçam a relação de mando-obediência, na qual o outro não é reconhecido como sujeito de direitos, como subjetividade e como alteridade. Assim, as vozes silenciadas e os corpos estigmatizados de mulheres vítimas de outras formas de opressão além do sexismo continuam na invisibilidade (Carneiro, 2003)

\section{Resultados e discussão}

Pela limitação de espaço deste artigo, optou-se por expor as matérias mais relevantes da bibliografia trabalhada. A primeira delas é do jornal Diário da Manhã - edição: DM025 10.942/2017 - cuja análise é colocada em destaque no Quadro 1. A matéria intitulada "Doméstica está assustada: 'se ele sair, ele me mata'" (Silva, 2017) expõe um caso ocorrido em 2017 e evidencia o descaso da população e, inclusive, das autoridades competentes que testemunharam a agressão, mas evitaram se envolver em "briga de marido e mulher". 


\begin{tabular}{|l|l|l|}
\hline \multicolumn{2}{|l|}{ UNIDADES DE REGISTRO } & CONSTRUÇõES DAS NOTícIAS \\
\hline $\begin{array}{l}\text { Comportamento } \\
\text { inadequado } \\
\text { da mulher }\end{array}$ & $\begin{array}{l}\text { "Está marcada para } \\
\text { porrer. É o que ela } \\
\text { alvejada cinco vezes } \\
\text { pelo namorado que não } \\
\text { aceitava o rompimento" } \\
\text { (Silva, 2017, p. 5). }\end{array}$ & $\begin{array}{l}\text { A realidade da mulher é } \\
\text { apresentada na realidade do } \\
\text { campo do bem e do mal, o leitor } \\
\text { é induzido a acreditar não só que } \\
\text { seja assim, mas também que não } \\
\text { há possibilidade de mudança } \\
\text { (Abramo, 2016). }\end{array}$ \\
\hline $\begin{array}{l}\text { Motivação } \\
\text { alegada do } \\
\text { agressor }\end{array}$ & $\begin{array}{l}\text { - Ele diz que estava } \\
\text { alcoolizado quando } \\
\text { praticou o crime. } \\
\text { (Silva, 2017). }\end{array}$ & $\begin{array}{l}\text { "O uso da bebida alcoólica e } \\
\text { de drogas é outra forma usual } \\
\text { de 'explicar' a violência contra } \\
\text { a mulher, produzindo uma } \\
\text { redução de sua complexidade } \\
\text { e, em decorrência disso, a sua } \\
\text { banalização" (Lima, 2001, p. 64). }\end{array}$ \\
\hline Imagens & $\begin{array}{l}\text { "A fotografia é utilizada para } \\
\text { garantir a realidade do fato } \\
\text { noticiado e, por isso, é tão } \\
\text { frequentemente usada nas } \\
\text { notícias de violência, sobretudo } \\
\text { nas de conteúdo chocante e } \\
\text { inacreditável” (Lima, 2001, p. 82). }\end{array}$ \\
\hline
\end{tabular}

Quadro 1: "Doméstica está assustada: 'se ele sair, ele me mata'" Nota: Neves e Moreira (2021).

$\mathrm{O}$ ato do agressor, apesar de ter ocorrido em uma via pública, não suscitou em quem presenciou a agressão nenhum gesto de solidariedade com a mulher, isto é, de socorrê-la, segundo a notícia. A mulher não recebeu ajuda nem mesmo dos agentes de segurança da Secretaria Municipal de Trânsito. Segundo Lima (2001), a compreensão das esferas públicas e privadas nos estudos de gênero é essencial: a primeira deve ser compreendida como o lugar natural dos homens, enquanto a segunda como o lugar das mulheres, em uma relação direta com os papéis de gênero.

Nesse sentido, apesar de a mulher ter sofrido a violência em via pública, a notícia denuncia a construção social dos espaços públicos e privados e sua relação direta com os papéis tradicionais de gênero. Parece haver naturalidade na aceitação social da violência, na medida em que as testemunhas evitam se envolver ainda que seja para salvar a vida da mulher. Em vista disso, Decarli (2017) sustenta que a violência de gênero é um terreno fértil no cenário de desigualdades e que dificilmente uma mulher sofre separadamente um único tipo de violência.

Observa-se, na construção da matéria analisada, uma reprodução das narrativas que legitimam a violência de gênero em outros campos sociais. Ela reforça que o agressor não aceitou o fim do relacionamento e, por esse motivo, decidiu ceifar a vida da ex-companheira. Segundo a narrativa do jornal, o agressor só agiu assim porque estava alcoolizado. Assim, o uso de bebida alcoólica e drogas é apresentado como uma forma usual de explicar a violência contra mulheres.

Desse modo, a construção do texto pode levar a entender que o consumo de bebidas corresponde diretamente à violência contra mulheres. A esse respeito, concordamos com Lima (2001) quando a autora afirma que o estado de embriaguez não deve ser utilizado pelas notícias como fator determinante para que a violência tenha ocorrido, mas como um elemento a mais na constituição do contexto em que aconteceu o crime.

Outra análise, referente à matéria do jornal O Popular - edição 23.190/2017 intitulada "Mulher foi torturada antes de ter o clitóris mutilado" (Araújo, 2017), é apresentada no Quadro 2. 


\begin{tabular}{|l|l|l|}
\hline \multicolumn{2}{|l|}{ UNIDADES DE REGISTRO } & $\begin{array}{l}\text { CONSTRUÇÕES DAS } \\
\text { NOTÍCIAS }\end{array}$ \\
\hline & $\begin{array}{l}\text { - Suspeita de traição; } \\
\text { - Denunciou o agressor } \\
\text { duas vezes antes e, } \\
\text { mesmo assim, reatou } \\
\text { o relacionamento; } \\
\begin{array}{l}\text { Comportamento } \\
\text { inadequado da } \\
\text { mulher }\end{array}\end{array}$ & - Culpabilização da mulher; \\
\hline $\begin{array}{l}\text { - Praticou sexo } \\
\text { oral no agressor. } \\
\text { (Araújo, 2017) }\end{array}$ & $\begin{array}{l}\text {-Desqualificação da mulher. } \\
\text { - Sempre foi muito } \\
\text { possessivo e ciumento; } \\
\text { - Alega que as agressões } \\
\text { praticadas foram } \\
\text { em legítima defesa. } \\
\text { (Araújo, 2017) }\end{array}$ & $\begin{array}{l}\text { - Patologização do } \\
\text { para justificar a agressão; }\end{array}$ \\
\hline machismo; \\
\hline Imagens
\end{tabular}

Quadro 2: "Mulher foi torturada antes de ter o clitóris mutilado" Nota: Neves e Moreira (2021).

Apesar do caráter chocante da violência narrada, esta é naturalizada como cena do cotidiano. A construção textual da notícia apresenta o clitóris mutilado com grande destaque, reforçando uma perspectiva de dominação da mulher violentada. Ao fazê-lo, contudo, transfere a responsabilidade do ato violento para o estado de descontrole emocional do agressor e culpa a vítima. Noticiase que, embora o agressor tivesse um comportamento possessivo e fosse ciumento e que a mulher o tenha denunciado outras vezes, o relacionamento teria sido reatado por ela. Ademais, reforçam-se elementos corriqueiros do discurso de legitimação da violência, marcadamente o sentimento de perda de propriedade da mulher.

A perspectiva masculinista hegemônica é legitimada no discurso veiculado pela matéria e vinculado a uma cultura de honra e orgulho, reiterando visões e práticas de controle sobre o corpo e a sexualidade da mulher (Machado, 1998). Cabe destacar que o discurso patológico do machismo, utilizado para justificar a atitude do agressor, pode favorecer a aceitação social da agressão, reforçando a perspectiva de que o agressor agiu violentamente por excesso de amor romantização da violência.

Outra matéria de destaque, também do jornal O Popular - edição 22.991/2017, justifica o ato violento do agressor com transtorno emocional: o homem não aceitou o fim do relacionamento e o seu transtorno teria sido agravado pelo uso de álcool. O título da matéria já sugere a ideia de forma embrionária: "Violência: fim de relacionamento teria motivado o cárcere" (Veloso, 2016). 


\begin{tabular}{|c|c|c|}
\hline \multicolumn{2}{|c|}{ UNIDADES DE REGISTRO } & $\begin{array}{l}\text { CONSTRUÇÕES DAS } \\
\text { NOTÍCIAS }\end{array}$ \\
\hline $\begin{array}{l}\text { Comportamento } \\
\text { inadequado da } \\
\text { mulher }\end{array}$ & $\begin{array}{l}\text { - Pouco tempo de } \\
\text { namoro, já tinha um } \\
\text { filho com o agressor e } \\
\text { quis a separação, mesmo } \\
\text { com uma criança recém- } \\
\text { nascida - } 40 \text { dias de vida. } \\
\text { (Araújo, 2017) }\end{array}$ & $\begin{array}{l}\text { - Desqualificação da mulher } \\
\text { ao relatar dados da sua vida } \\
\text { íntima na notícia. }\end{array}$ \\
\hline $\begin{array}{l}\text { Motivação } \\
\text { alegada do } \\
\text { agressor }\end{array}$ & $\begin{array}{l}\text { - Ele não aceitou o fim do } \\
\text { relacionamento, bebeu } \\
\text { muito, prendeu todos } \\
\text { em sua casa e passou a } \\
\text { ameaçar todos de morte; } \\
\text { - Fez tratamento } \\
\text { espiritual outras vezes } \\
\text { e estava bem, mas é só } \\
\text { beber que ele começa. } \\
\text { (Araújo, 2017) }\end{array}$ & $\begin{array}{l}\text { - A justificativa do agressor, } \\
\text { segundo a notícia, é estar } \\
\text { emocionalmente abalado } \\
\text { e bêbado; } \\
\text {-Tem histórico de } \\
\text { comportamento agressivo, } \\
\text { que piora com o uso } \\
\text { da bebida; } \\
\text { - Patologização do machismo. }\end{array}$ \\
\hline Imagens & $\begin{array}{l}\text { - Sem imagens. } \\
\text { (Araújo, 2017) }\end{array}$ & - Não se aplica. \\
\hline
\end{tabular}

Quadro 3: "Violência: fim de relacionamento teria motivado o cárcere" Nota: Neves e Moreira (2021).

O texto traz elementos que justificam o ato violento do homem, que não aceitou o fim do relacionamento e teve seu transtorno supostamente agravado pelo consumo de álcool. Nesse sentido, relaciona-se o ato violento com o estado de insensatez, o perpetrador deixa de ser responsável pela violência praticada e a responsabilidade é depositada na substância psicoativa, o que chamamos, aqui, de patologização do machismo. Pelos elementos envolvidos na construção da matéria, é possível verificar uma concentração de percepções falaciosas, em que a mulher violentada é considerada inferior no ordenamento das relações sociais. Além disso, a notícia remete, também, à ideia de propriedade sexual, isto é, o controle do corpo feminino pela masculinidade hegemônica (Bandeira \& Magalhães, 2019, p. 41 citado por Connel, 2010; Wilson \& Daly, 1998).

A narrativa analisada reforça o sentimento de posse que o perpetrador estabelece na sua relação com a mulher vitimada, procurando submetê-la à condição de objeto, o que fornece condições que legitimam, viabilizam e perpetuam as violências. Outros fatores, como bebida ou drogas, são elementos que auxiliam na manifestação de comportamentos violentos, porque podem aumentar o estresse e, também, porque reduzem o controle ou a censura.

Nesse sentido, as mulheres, que até os dias atuais passam por interdições no espaço público, sofrem violência doméstica no interior de suas relações familiares. Os agressores são, majoritariamente, (ex-)maridos, (ex-)companheiros e (ex-namorados (Safiotti, 2004). Assim, a violência contra mulheres "não se caracteriza como patologia ou como desvio individual, mas sim como permissão social concedida e acordada com os homens na sociedade" (Bandeira, 2014, p. 461).

O último caso, apresentado no Quadro 4, também foi veiculado no jornal O Popular - edição: 23.903/2017. A violência, resultado do ciúme do agressor, é apresentada sob o título "Bastante ferida, jovem é resgatada após sequestro por ex" (Melo, 2016). Cansada de ser agredida pelo namorado, a jovem terminou o relacionamento e ficou dois meses em São Paulo. Ao voltar, foi feita refém na própria casa. 


\begin{tabular}{|c|c|c|}
\hline \multicolumn{2}{|c|}{ UNIDADES DE REGISTRO } & CONSTRUÇÕES DAS NOTÍCIAS \\
\hline $\begin{array}{l}\text { Comportamento } \\
\text { inadequado da } \\
\text { mulher }\end{array}$ & $\begin{array}{l}\text { - Namorou o agressor, } \\
\text { tendo conhecimento de que } \\
\text { ele tinha várias passagens } \\
\text { pela polícia; } \\
\\
\text { - Ele foi se tornando mais } \\
\text { violento conforme o namoro } \\
\text { avançava (Melo, 2016) }\end{array}$ & - Culpabilização da mulher. \\
\hline $\begin{array}{l}\text { Motivação } \\
\text { alegada do } \\
\text { agressor }\end{array}$ & $\begin{array}{l}\text { - Ele não aceitou o fim do } \\
\text { relacionamento e passou a } \\
\text { ameaçar e espancar a ex, } \\
\text { mantendo a vítima presa em } \\
\text { sua residência. (Melo, 2016) }\end{array}$ & $\begin{array}{l}\text { - A justificativa do agressor, } \\
\text { segundo a notícia, é que } \\
\text { ele estava emocionalmente } \\
\text { abalado e bêbado; } \\
\text { - O agressor tem histórico de } \\
\text { comportamento agressivo, } \\
\text { que piora com o uso } \\
\text { da bebida; } \\
\text { - Patologização do machismo. }\end{array}$ \\
\hline Imagens & $\begin{array}{l}\text { - Uma mulher jovem } \\
\text { olhando pela janela. } \\
\text { (Melo, 2016) }\end{array}$ & $\begin{array}{l}\text { - A mulher em vulnerabilidade } \\
\text { social. }\end{array}$ \\
\hline
\end{tabular}

Quadro 4: "Bastante ferida, jovem é resgatada após sequestro por ex" Nota: Neves e Moreira (2021).

Para Bandeira (2017), a violência presente nas relações interpessoais de gênero é estruturante, o que acaba normatizando, modelando e regulando as relações entre homens e mulheres, seja pela forma de poder que a estrutura da violência assume, seja pela dimensão qualitativa que ela apresenta, por exemplo, a mulher receber ameaças de morte do seu ex-namorado e passar a ser refém na própria casa. Quando as mulheres não desejam permanecer em uma relação, elas são ameaçadas ou agredidas. Instaura-se, assim, um ciclo de violência e, na maioria das vezes, a patologização do machismo, tanto em matérias jornalísticas como em representações sociais mais amplas. A patologização do machismo funciona como um recurso para eximir ou minimizar a responsabilidade social em crimes, bem como relações de poder desiguais e hierárquicas entre homens e mulheres, manifestadas sobre o corpo das mulheres pela condição hegemônica e estrutural da dominação masculina (Bandeira, 2017). Na narrativa analisada, são reproduzidas concepções que tendem a apresentar o machismo como elemento inerente a todos os homens, assim como a submissão como algo inerente às mulheres.

Acreditamos, após a análise de tais matérias jornalísticas, que os discursos midiáticos têm o potencial de naturalizar as violências sofridas por mulheres e, por essa via, perpetuar as desigualdades de gênero. Esses discursos estabelecem uma relação de poder entre a mídia e a sociedade, reforçando a discriminação contra mulheres e estimulando outras formas de violência. Concordamos com Lima (2001) quando a autora afirma que:

A divulgação da violência contra a mulher através das mídias tende a reforçar as desigualdades de gênero, ou seja, quando a mulher tem sua vida exposta, esta é submetida a mais uma forma de violência, como manchetes e fotos. (Lima, 2001, p. 20)

Neste contexto, acredita-se que, nas narrativas jornalísticas analisadas, a representação da violência de gênero contra mulheres reverbera dimensões estruturantes da sociedade não só goiana, mas também brasileira, que dimensionam relações de poder a partir das construções de gênero. As matérias, ainda, culpabilizam a mulher quando afirmam que, apesar de o agressor ter várias passagens pela polícia, a mulher vitimada escolheu se relacionar com ele. 
Existem certos paralelos entre os ritmos narrativos dos jornais Diário da Manhã e o Popular, pois ambos têm uma estrutura dualista que opõe vítima e agressor de maneira a obscurecer a complexidade das situações em que a violência de gênero ocorre (Gregori, 1993), sendo importante observar que a forma como os jornais têm acesso aos fatos delimita os elementos relevantes para a compreensão da violência.

A partir disso, quando essas narrativas naturalizam a violência contra mulheres, por meio da divulgação de notícias que promovem cotidianamente situações de violência permeadas e potencializadas pelas desigualdades sociais, elas não só encobrem um problema social e estrutural - a violência contra mulheres e a violação dos direitos humanos -, mas também assumem o papel de agentes nesse processo. Nessa dinâmica, que se processa a partir da violência simbólica, funda-se um processo de revitimização. Para Sanematsu (2011, pp. 98-99):

A mídia hoje é responsável pela veiculação dos assuntos e dos acontecimentos ocorrentes no cotidiano, é uma fonte de pesquisa muito importante, fundamental nas questões informacionais, desempenhando um papel relevante, seja de valor negativo ou positivo da realidade. Representa um espaço destinado ao debate que se constitui em uma forma de pressão aos poderes públicos, pois, ao noticiar os fatos e demonstrar o drama humano, o jornalismo pode aproveitar e direcionar seu foco para a questão das políticas públicas voltadas para as medidas preventivas no fenômeno da violência contra a mulher, nas esferas federal, estadual e municipal e nos âmbitos assistencial, reeducacional e punitivo.

Isto posto, as narrativas dos jornais Diário da Manhã e O Popular analisadas refletem como as mulheres são sujeitadas a vários tipos de violência, desde aquela que atinge seus corpos e visa sua desumanização por meio da mutilação, até a violência simbólica, que representa uma destruição identitária da mulher como sujeito de direitos. Apesar dos avanços constatados na produção jornalística como prática narrativa, ainda são corriqueiras as notícias que desqualificam e culpabilizam as mulheres, bem como justificam as atitudes do agressor, seja pela atribuição do crime à passionalidade, seja pela patologização do machismo. Todo um imaginário sobre as mulheres é criado e utilizado para naturalizar as violências em relação ao gênero (Bourdieu, 2019).

Desse modo, por meio dos elementos da construção jornalística, é possível afirmar que as narrativas analisadas, veiculadas pelos jornais Diário da Manhã e O Popular, reproduzem dinâmicas relacionadas à moralidade, à passionalidade e à dominação masculina. Não é apresentada uma representação ou reflexão qualificada sobre os processos de violência de gênero contra as mulheres que reportam a violência, muito menos sobre as consequências da denúncia. As mulheres vitimadas são retratadas de forma a culpabilizá-las e desqualificá-las. Legitimando as ações do agressor, faz-se frequentemente referência às justificativas relacionadas ao consumo de substâncias psicoativas.

\section{Conclusão}

Procurou-se estudar, neste artigo, o processo de revitimização feminina a partir das representações do jornalismo impresso goiano. Foram analisadas 17 notícias de dois dos jornais de maior circulação do estado - O Popular e Diário da Manhã. O objetivo específico foi compreender como a patologização da agressão - compreendida como o processo a partir do qual a responsabilidade pela agressão cometida é simbólica e socialmente atenuada ou extinta, a partir da constatação de que o perpetrador agiu sob a influência de substâncias psicoativas - é mobilizada nas narrativas jornalísticas, analisadas de maneira a legitimar as agressões e auxiliar na culpabilização das mulheres vitimadas.

Os dados obtidos pelos casos noticiados nos dois veículos demonstraram que há uma permanência das mulheres na condição de vítima, introjetando a ideia de que mulheres em situação de violência não são sujeitas autônomas e, nessa via, as justificativas abordadas permeiam variantes referentes à dominação masculina. A cobertura midiática relacionada à violência contra as mulheres deve buscar meios de não omitir a violação dos direitos humanos das mulheres e evitar fundamentar 
as desigualdades sociais aos papéis de gênero. De igual modo, é preciso reconhecer que os atos violentos não são justificáveis pela "motivação" dos agressores ou pela desqualificação e culpabilização das mulheres, pois essas são as bases da violência simbólica e contribuem para instalar o processo de revitimização.

Concluiu-se, assim, que as matérias jornalísticas apresentam conteúdos e narrativas estruturadas a partir de regimes simbólicos presentes em outros campos da vida social e que agem de forma a naturalizar relações violentas e desiguais. Nesse processo, as dinâmicas jornalísticas também assumem, em uma dimensão simbólica, o papel de agentes de violência. É precisamente em tal dimensão que se encontra a dinâmica da revitimização midiática.

A compreensão do papel da mídia na dinâmica da violência de gênero contra mulheres, principalmente quando relaciona a ocorrência da violência ao uso de substâncias psicoativas ou ao álcool e legitima os atos de violência, tem o potencial de tornar pouco visíveis os fenômenos das desigualdades de gênero, de produzir uma redução da sua complexidade e, em decorrência disso, de banalizá-la (Lima, 2001). Certamente uma mudança na dinâmica das agressões motivadas por gênero passa por uma reformulação estrutural das características predominantes na imprensa tanto goiana quanto brasileira.

\section{REFERÊNCIAS}

ABRAMO, P. (2016). Padrões de manipulação na grande imprensa. Perseu Abramo.

Araújo, N. (2017). Mulher foi torturada antes de ter o clitóris mutilado. O Popular. https://opopular.com.br/noticias/cidades/mulher-foi-torturada-antes-de-ter-oclit\%C3\%B3ris-mutilado-1.1301557

Bandeira, L. M. (2014). Violência de gênero: A construção de um campo teórico e de investigação. Sociedade e Estado, 29(2), 449-469. https://doi.org/10.1590/ S0102-69922014000200008

Bandeira, L. M. (2017). Violência, gênero e poder: Múltiplas faces. In C. Stevens, S. Oliveira, V. Zanello, E. Silva \& C. Portela (Orgs.), Mulheres e violências: Interseccionalidades (pp. 14-35). Technopolitik.

Bandeira, L. M., \& Magalhães, M. J. (2019). A transversalidade dos crimes de femicídio/feminicídio no Brasil e em Portugal. Revista da Defensoria Pública do Distrito Federal, 1(1), 29-56.

Bardin, L. (2016). Análise de conteúdo. Edições 70.

Bourdieu, P. (2019). A dominação masculina (5a ed.). Bertrand Brasil.

Carneiro, A. S. (2003). Mulheres em movimento. Estudos Avançados, 17(49), 117137. https://doi.org/10.1590/S0103-40142003000300008

Chauí, M. (1985). Participando do debate sobre mulher e violência. In B. Franchetto, M. L. V. Cavalcanti \& M. L. Heilborn (Orgs.), Perspectivas antropológicas da mulher (v. 1, pp. 23-62). Zahar.

Cunha, R. S., \& Pinto, R. B. (2008). Violência doméstica: Lei Maria da Penha11.340/2006 comentada artigo por artigo (2a ed.). Revista dos Tribunais.

DECARLI, M. O. (2017). O Partejar e a Violência Obstétrica: silenciosa violência e a violência do silêncio. [Dissertação, Universidade Federal do Rio de Janeiro]. UFRJ.

Drogas: classificação e feitos no organismo. (s.d.). Faculdades Adamantinenses Integradas. http://www.fai.com.br/portal/pibid/adm/atividades_anexo/74df176 f30bca479a211a121bfbc6a40.pdf 
Gregori, M. F. (1993). Cenas e queixas um estudo sobre mulheres, relações violentas e a prática feminista. Paz e Terra.

Lamas, M. (2000). Diferencias de sexo, género y diferencia sexual. Cuicuilco, 7(8), 1-24.

Lima, A. P. (2001). A notícia de violência contra a mulher e a violência da notícia. [Dissertação de mestrado, Universidade Federal de Goiás]. Cercomp UFG.

Machado, L. Z. (1998). Gênero: um novo paradigma? Cadernos Pagu, (11), 107-125.

Moura, S. N. C. (2017). Estupro de mulheres como crime de guerra: Lições sobre direito, feminismo e vitimização. Servanda.

Melo, R. (2016, 16 de setembro). Bastante ferida, jovem é resgatada após sequestro por ex. O Popoular. https://opopular.com.br/noticias/cidades/bastante-feridajovem-\%C3\%A9-resgatada-ap\%C3\%B3s-sequestro-por-ex-1.1149138

Neves, A. P. C. (2021). Além das narrativas jornalísticas e policiais: Uma análise sobre a revitimização das mulheres em situação de violência de gênero institucional [Dissertação de mestrado, Universidade Federal de Goiás]. Cercomp UFG.

Neves, A. P. C., \& Moreira, R. D. (2021, 19-30 de julho). A culpabilização das mulheres nas narrativas sobre violência de gênero nos boletins de ocorrência e nos jornais diários de Goiânia [Trabalho apresentado]. Seminário internacional fazendo gênero 12, Santa Catarina, SC, Brasil.

Saffioti, H. I. B. (2004). Gênero e patriarcado: Violência contra mulheres. In G. Venturi, M. Recamán \& S. Oliveira (Orgs.), A mulher brasileira nos espaços público e privado (pp. 43-60). Fundação Perseu Abramo.

Sanematsu, M. (2011). Análise da cobertura da imprensa sobre violência contra as mulheres. In V. Vivarta (Ed.), Imprensa e agenda de direitos das mulheres: Uma análise das tendências da cobertura jornalística (pp. 55-104). ANDI; Instituto Patrícia Galvão.

Silva, B. (2017, 30 de setembro). Doméstica está assustada: "Se ele sair, ele me mata". Diário da Manhã. http://impresso.dm.com.br/edicao/20170930/pagina/5

Wilson, M. \& Daly, M. (1998). Sexual Rivalry and Sexual Conflict: Recurring Themes in Fatal Conflicts. Theoretical Criminology, 2(3), 291-310. 